\title{
Psychiatric disorders and fitness to drive
}

Gérard Niveau and Melissande Kelley-Puskas Institute of Forensic Medicine, University of Geneva, Switzerland

\begin{abstract}
Objective-In Switzerland, as in some other European countries, medical doctors may breach patient confidentiality and report to police authorities any patient who seems prone to automobile accidents or traffic violations. The aim of this study was to see if those patients reported to authorities actually represent a higher risk than drivers not reported to the police. Design-This study was designed following a case-control study comparing the characteristics of a group of psychiatric patients who were reported to authorities for preventive purposes, with the characteristics of another group of people who had disorders that were noticed at the time of an accident or traffic violation.

Results-The results show that medical doctors tended to report male patients, patients with a low level of education, and patients with a severe psychiatric background. The subjects of the control group, who had often been involved in accidents or committed traffic violations in the past, did not possess these characteristics.

Conclusions-The breach of medical confidentiality by doctors in reporting to authorities patients who are allegedly at risk is ethically questionable as long as the evaluation of driving performance does not rely on objective bases.

(Fournal of Medical Ethics 2001;27:36-39)
\end{abstract}

Keywords: Driving performance; mental health information; traffic accidents; violation; psychiatric disorders and fitness to drive

Traffic accidents, being an important source of morbidity and mortality, represent a real public health challenge. Many approaches have been tried to identify potentially dangerous drivers, ${ }^{1}$ and the concept of "accident proneness" introduced by Greenwood and Woods, ${ }^{2}$ has been applied to road traffic since the postwar period. ${ }^{3}$

From that point of view, mentally ill people have been viewed as dangerous drivers, sometimes without serious epidemiological basis. ${ }^{4}$ When studies were performed, results showed that the question of allowing the mentally disturbed to drive was indeed quite complex. Psychiatric patients as a whole do not present a greater risk than the general population, ${ }^{5}$ except in cases of an alcohol or drug comorbidity ${ }^{67}$ Nevertheless, patients with personality or psychoneurotic disorders have high accident rates, ${ }^{89}$ while psychiatric subjects, who drive far less than matched nonpsychiatric controls, have more accidents per miles driven, ${ }^{10}$ with specific characteristics. ${ }^{112} \mathrm{~A}$ pilot study by Elkema et $a l^{13}$ reveals the benefits of treatment in all categories of disorders, with the exception of personality disorders.

Medical doctors have a responsibility in the prevention of accidents and violations due to their patients' mental disorders. ${ }^{145}$ Yet the effectiveness of this prevention is difficult to measure since once a patient stops driving, it can longer be known if he or she was ever really a driver prone to traffic accidents.

The aim of this study was to compare the medical characteristics and driving records of a sample of psychiatric patients who were reported to authorities by doctors for prevention with those of a control group who were suffering from mental disorders at the time of an accident or a violation.

\section{Method}

MEDICAL-LEGAL BASIS

In Switzerland, federal law on road traffic stipulates that any medical doctor may report to the authorities a person not deemed capable of driving a vehicle safely due to illness, physical or mental disability, or drug addiction. In such cases, the driver's licence of the reported person is systematically revoked and it may only be returned once the subject obtains positive results in a psychiatric expert's report.

In the Canton of Geneva, the University Institute of Forensic Medicine conducts all expert reports in the evaluation of a driver's aptitude. There are approximately 400,000 people living in the canton.

\section{SUBJECTS AND PROCEDURE}

The study was designed from a case-control study model, adapted to the low number of subjects available. Of all the driving aptitude evaluations carried out by the Forensic Institute in Geneva between 1993 and $1998(\mathrm{n}=1,858)$, we selected those subjects who were there because they had shown signs of mental disorders $(n=81)$.

We excluded subjects whose psychiatric disease was not the main disorder, those who did not already have a driving licence (evaluations for new drivers), and those living outside of the canton.

Finally, we retained a group of 65 subjects whom we categorised according to the reasons for having their driving privileges revoked. The 31 patients who were reported to the authorities by a medical doctor made up the case group, while the 34 subjects who had their licences revoked for having an established mental disorder at the time of an accident or violation constituted the controls. 
Data were collected from the experts' files on the subjects as well as from their driving records from the bureau of motor vehicles in the canton. The data that were collected covered sociodemographic factors, medical factors and past driving history.

The psychiatric antecedents were divided into three groups: none or mild (without any antecedent, no, or one short, hospitalisation, outpatient follow up for less than one year); moderate (few, short hospitalisations, outpatient follow up for one or more years); and severe (many or long hospitalisations).

Likewise, driving antecedents were classified by adding up the number of violations and accidents based on the driving records of the subjects. We separated them according to no or mild antecedents (no, or one, accident or violation), moderate (two to four); and severe (more than four).

The protocol was submitted to an ethics commission for approval. Each subject was informed of the protocol and provided prior, written agreement to participation.

\section{STATISTICAL ANALYSIS}

Dichotomous variables were compared by way of the $\chi$-square test and continuous variables were compared using the Student's $t$-test.

To explore the possible predictors of being reported compared with an accident or a traffic violation, a logistic regression analysis was used with "being reported for prevention" as the dependent variable and gender, living arrangements, level of schooling, professional situation, psychiatric antecedents and driving antecedents as the independent variables.

All analyses were two-tailed. A conventional level of statistical significance was used $(\alpha=0.05)$. The calculations were done using Statistical Package for Social Sciences (SPSS) software.

\section{Results}

We were able to collect all of the data for the 65 subjects who were selected. The mean age of the subjects who were reported to the authorities (37.1 years of age, $\mathrm{sd}=10.2$ ) was not significantly different $(t=0.69)$ from the mean age of the control subjects (38.2 years of age, sd $=11.5$ ). Table 1 illustrates that, among other sociodemographic factors, gender and level of schooling were the most important differences between the two groups; that is, there were more males and less schooling among the subjects who were reported to authorities.

Table 2 summarises the distribution of diagnoses in the different groups. If we group together on one hand the chronic disorders and, on the other, the acute disorders, a significant difference appears $(\chi 2$ $=4.95, \mathrm{df}=1, \mathrm{p}<0.05)$, meaning there is a higher rate of acute disorders among the reported-forprevention cases than the controls.

At the time they were preventively reported to the authorities, 15 subjects (48\%) were being treated with at least two psychotropics and 17 $(50 \%)$ of the control group were receiving this form
Table 1 Sociodemographic factors of subjects reported to authorities and controls

\begin{tabular}{lllll}
\hline & $\begin{array}{l}\text { Subjects } \\
\text { reported for } \\
\text { prevention } \\
n=31\end{array}$ & $\begin{array}{l}\text { Controls } \\
\text { (accidents or } \\
\text { violations) } \\
n=34\end{array}$ & $\chi^{2}(d f)$ & $P$ \\
\hline $\begin{array}{l}\text { Gender (Male) } \\
\text { Living arrangements }\end{array}$ & $26(83.9)$ & $18(52.9)$ & $7.09(1)$ & $<0.01$ \\
$\quad \begin{array}{l}\text { Married or } \\
\text { cohabitation }\end{array}$ & $8(25.8)$ & $7(20.6)$ & & \\
$\begin{array}{l}\text { Single } \\
\text { With parents }\end{array}$ & $8(25.8)$ & $11(32.4)$ & $0.70(3)$ & NS \\
$\begin{array}{l}\text { Other } \\
\text { Level of schooling }\end{array}$ & $7(25.8)$ & $10(30.4)$ & & \\
$\begin{array}{l}\text { Obligatory } \\
\text { school }\end{array}$ & $17(54.8)$ & $8(23.5)$ & & \\
$\begin{array}{l}\text { Secondary - } \\
\text { apprenticeship }\end{array}$ & $11(35.5)$ & $18(52.9)$ & $7.08(2)$ & $<0.05$ \\
$\quad \begin{array}{l}\text { University } \\
\text { Employment }\end{array}$ & $3(9.7)$ & $8(23.5)$ & & \\
$\begin{array}{l}\text { Stable } \\
\text { employment }\end{array}$ & $6(19.4)$ & $7(20.6)$ & & \\
$\begin{array}{l}\text { Occasional } \\
\text { employment }\end{array}$ & $7(22.6)$ & $13(38.2)$ & $3.34(3)$ & NS \\
$\begin{array}{l}\text { Unemployment } \\
\text { Pension }\end{array}$ & $8(25.8)$ & $7(20.6)$ & & \\
\hline & $10(32.3)$ & $7(20.6)$ & & \\
\hline
\end{tabular}

Table 2 Diagnoses of subjects reported to authorities and controls

\begin{tabular}{lllll}
\hline & $\begin{array}{l}\text { Subjects } \\
\text { reported for } \\
\text { prevention } \\
n=31\end{array}$ & $\begin{array}{l}\text { Controls } \\
\text { (accidents or } \\
\text { violations) } \\
n=34\end{array}$ & $\chi^{2}(d f)$ & $P$ \\
\hline $\begin{array}{l}\text { Acute psychotic } \\
\text { disorder }\end{array}$ & $4(12.9)$ & $9(26.5)$ & & \\
$\begin{array}{c}\text { Chronic psychotic } \\
\text { disorder }\end{array}$ & $13(41.9)$ & $6(17.6)$ & & \\
$\begin{array}{c}\text { Acute mood } \\
\text { disorder }\end{array}$ & $6(19.4)$ & $9(26.5)$ & $7.38(4)$ & NS \\
$\begin{array}{c}\text { Chronic mood } \\
\text { disorder }\end{array}$ & $6(19.4)$ & $4(11.8)$ & & \\
$\begin{array}{l}\text { Others } \\
\text { Others }\end{array}$ & $2(6.5)$ & $6(17.6)$ & & \\
\hline
\end{tabular}

of treatment at the time of the accident or violation. The treatments of the subjects in both groups were very heterogeneous and a significant difference could not be noticed.

The comorbidity was rather high in both groups, yet not significantly different. Among the cases, four subjects $(13 \%)$ had a somatic disease and five $(16 \%)$ were suffering from drugs or alcohol abuse or addiction (cannabis excluded). The results for the controls were, respectively, five subjects $(15 \%)$ for somatic comorbidity and seven subjects (20\%) for drug and alcohol comorbidity.

The antecedents of the two groups were definitely different (table 3): the subjects who were preventively reported to the authorities, as opposed to the actual perpetrators of accidents or violations, usually showed severe psychiatric antecedents, yet almost half of them had very clean driving records. Less than $10 \%$ of the control group had previously clean driving records.

Table 4 shows the predicting factors for a subject being reported for prevention rather than having an accident or committing a violation. The logistic regression made it possible to eliminate the 
Table 3 Psychiatric and traffic antecedents of subjects reported to authorities and controls

\begin{tabular}{|c|c|c|c|c|}
\hline & $\begin{array}{l}\text { Subjects } \\
\text { reported for } \\
\text { prevention } \\
n=31\end{array}$ & $\begin{array}{l}\text { Controls } \\
\text { (accidents or } \\
\text { violations) } \\
n=34\end{array}$ & $\chi^{2}(d f)$ & $P$ \\
\hline \multicolumn{5}{|c|}{ Psychiatric antecedents } \\
\hline None or mild & $3(9.7)$ & $15(44.1)$ & & \\
\hline Moderate & $8(25.8)$ & $10(29.4)$ & $12.28(2)$ & $<0.05$ \\
\hline Severe & $20(64.5)$ & $9(26.5)$ & & \\
\hline \multicolumn{5}{|c|}{ Driving antecedents } \\
\hline None or mild & $14(45.2)$ & $3(8.8)$ & & \\
\hline Moderate & $12(38.7)$ & $17(50.0)$ & $12.13(2)$ & $<0.01$ \\
\hline Severe & $5(16.1)$ & $14(41.2)$ & & \\
\hline
\end{tabular}

Table 4 Possible predictors of being reported (logistic regression)

\begin{tabular}{lrlr}
\hline & Odds ratio & CI 95\% & \\
\hline Male & 4.62 & 1.50 & 14.26 \\
Severe psychiatric antecedents & 11.11 & 2.78 & 44.43 \\
Severe road traffic antecedents & 0.08 & 0.01 & 0.44 \\
\hline
\end{tabular}

(CI = confidence interval)

diagnosis and the level of schooling as a predicting factor. The subject's gender (male) and severity of psychiatric antecedents increased the risk of being reported to authorities by a medical doctor, while severe driving antecedents, paradoxically, reduced this risk.

\section{Discussion}

The results must be interpreted very carefully because of the small sample size used in this study. Using the case-control study methodology makes it possible to reduce the disadvantages related to the small number of subjects, but leads to other risks specific to this kind of study. In particular, we cannot entirely eliminate the possibility of self selection of the cases by the disease itself. However, this bias has little effect if we consider that the aim of the study was to look at those cases that were actually reported to the authorities by medical doctors, and not those whom doctors would have reported had they been aware of all cases. Furthermore, the lack of pairing and randomisation of the controls is balanced out by the fact that patient recruitment was exhaustive and carried out in a well-defined geographic area, and that the groups were very close to one another in terms of age structure.

The main result of the study is the distinct difference between characteristics in the one group of patients who were reported to the authorities, and those of the group for whom disorders had been established at the time of a violation or an accident. The results can be interpreted in a variety of ways. On the one hand, they tend to show that medical doctors report patients to the authorities according to their own professional criteria, such as the seriousness of the disease and the severity of medical antecedents. They base their opinion on instinctive notions such as male gender or level of schooling, while underestimating the driver's be- haviour and driving record, which can lead to mistakes in the evaluations. For exemple the Karstrup study $^{12}$ shows an over-representation of females, and not males, involved in accidents related to psychiatric disease.

The results of the study also tend to show that patients involved in accidents fall through the cracks of the medical system, either because of their disease or their personality. This has been confirmed by studies showing that the proneness to accidents of some subjects depends on factors such as impulsiveness or reactions to stress, which do not always give rise to medical intervention. ${ }^{16}$ Furthermore, it's logical that some acute states of mental disease escape from the care network and are only revealed at the time of an accident or a violation. In a study conducted in 1990 which only covered accidents, Cushman ${ }^{17}$ reported the low percentage of subjects with acute mental disorders who receive regular medical care.

Finally, our study could raise fears that the patients who are reported to authorities are indeed not really predisposed to traffic infractions or accidents, whereas those who actually are do not get reported. However, other interpretations can be made. Indeed, our study does not formally establish that the patients who are reported for preventive reasons would not have also represented a risk for road safety had they continued to drive. Indeed, several factors may play a role in cases of infractions or accidents, while the actual role of the mental illness, when it does exist, is complex to analyse. It is possible, and even likely, that a certain number of people with pyschological disorders do drive yet do not have accidents or committ infractions. These people are not covered in studies like ours. The risk that they represent may depend on interacting factors and is often not evaluated.

The real prevalence of mental disorders as a human factor playing a role in car accidents or traffic violations should be analysed further by cross-studies based on larger samples. Such research, carried out by Ohlberd et $a l^{13}$ on car suicides, shows that once the problems of methodological biases are under control, the mental disorder rates are much higher than what gets reported in official statistics.

It remains essential to supply psychiatrists and general practitioners with new information, which is quantitatively as well as qualitatively valid, on the real nature and role of mental disorders in automobile accidents and traffic violations.

The problem of how to assess the ability to drive should be treated more thoroughly in the training and education of physicians, and not only within the scope of counter-indications due to medical treatments. It is indeed a classical ethical question involving a confrontation between the interest of the individual, and his or her confidentiality rights, and the interest of society, in ensuring road safety.

If we admit that practitioners have a responsibility to ensure public safety and that, for ethical reasons, the breach of medical confidentiality must only concern very dangerous cases, then the 
reporting of subjects to the authorities must not be based on instincts, but rather on scientific knowledge of the danger actually posed by the patient's predisposition to accidents.

Under Swiss law, the physician may, but is not obliged to, report to authorities those patients whom he or she believes to be at risk. The ethical issue thus remains entirely up to the physician to resolve, yet as we have seen, the physician does not have the right scientific means to make such choices. This situation leads to arbitrary and unfair decisions. Alternative proposals may be to make it mandatory for physicians to report to the authorities cases of psychosis, severe mood disorders, and dependence on, or chronic abuse of drugs or alcohol, as well as organic disorders leading to a psychiatric disability. In all these cases, a medical examination leading to the production of a report could be carried out to evaluate the patient's ability to drive. This report would record, following the examination, not only the medical aspects but also the driving record of the person concerned. Anyone who had his driving licence revoked on medical grounds would have the right to appeal.

This way of handling the problem of how to assess the ability to drive of the mentally ill would probably be more fair and more equitable and allow for better prevention measures. There may be a certain number of patients who are dangerous drivers and who are unknown to physicians, but such is the price for personal freedom.

Gérard Niveau, MD, is Lecturer in Forensic Psychiatry at the Faculty of Medicine, University of Geneva, Switzerland. Melissande Kelley-Puskas, MD, is Assistant Psychiatrist at the Institute of Forensic Medicine, University of Geneva.

\section{References}

1 Benton JL, Mills L, Hartman K, Crow JT. Auto driver fitness: an evaluation of useful criteria. Fournal of the American Medical Association 1961;176:419-28.

2 Greenwood M, Woods HM. The incidence of industrial accidents. Reports Industrial Research Board 1919;10:4-20.

3 Ohberg A, Penttila A, Lonnqvist J. Driver suicide. British fournal of Psychiatry 1997;171:468-72.

4 Waller JA. Chronic medical conditions and traffic safety. New England fournal of Medicine 1965;273:1413-20.

5 Buttiglieri $M$, Guenette $M$. Driving record of neuropsychiatric patients. Fournal of Applied Psychology 1967;51:96-100.

6 Maki M, Linnoila M. Traffic accident rates among Finnish out-patients. Accident Analysis and Prevention 1976;8:39-44.

7 Armstrong JL, Whitlock FA. Mental illness and road traffic accidents. Australian and New Zealand Fournal of Psychiatry 1980;14:53-60

8 Crancer A, Quiring DL. The mentally ill as motor vehicle operators. American fournal of Psychiatry 1969;126:807-13.

9 Tsuang MT, Boor M, Fleming JA. Psychiatric aspects of traffic accidents. American fournal of Psychiatry 1985;142:538 46.

10 Edlund MJ, Conrad C, Morris P. Accidents among schizophrenic outpatients. Comprehensive Psychiatry 1989;30:522-6.

11 Iancu I, Spivak B, Wiener A, Weizman A. Psychiatric guidelines for licensing drivers. International Fournal of Risk and Safety in Medicine 1996;8:169-73.

12 Kastrup M, Dupont A, Bille M, Lund H. Traffic accidents involving psychiatric patients. Acta Psychiatrica Scandinavia 1977;55:355-68.

13 Eelkema RC, Brosseau J, Koshnick R, McGee C. A statistical study on the relationship between mental illness and traffic accidents-a pilot study. American fournal of Public Health 1970; 60:459-69.

14 Metzner JL, Dentino AN, Godard SL, Hay DP, Hay L, Linnoila M. Impairment in driving and psychiatric illness. fournal of Neuropsychiatry 1993;5:211-20.

15 Petch E. Mental disorder and fitness to drive. The fournal of Forensic Psychiatry 1996;7:607-18.

16 Iancu I, Spivak B, Dannon PN, Wiener A, Weizman A. Psychiatric and psychological aspects of traffic accidents: a review. Fournal of Traffic Medicine 1996;24:17-21.

17 Cushman LA, Good RG, States JD. Psychiatric disorders and motor vehicle accidents. Psychological Reports 1990;67:483-9. 